AperTO - Archivio Istituzionale Open Access dell'Università di Torino

\title{
Impact of new interconnection lines on the EU electricity market
}

\section{This is the author's manuscript}

Original Citation:

\section{Availability:}

This version is available http://hdl.handle.net/2318/1686820

since 2019-01-14T17:50:05Z

Terms of use:

Open Access

Anyone can freely access the full text of works made available as "Open Access". Works made available under a Creative Commons license can be used according to the terms and conditions of said license. Use of all other works requires consent of the right holder (author or publisher) if not exempted from copyright protection by the applicable law. 


\section{Impact of new interconnection lines on the $\mathrm{EU}$ electricity market}

\author{
Valeria Di Cosmo \\ ESRI and \\ Trinity College Dublin \\ Email: valeria.dicosmo@esri.ie
}

\author{
Valentin Bertsch \\ ESRI and \\ Trinity College Dublin
}

\author{
Paul Deane \\ Energy Policy and Modelling Group, ERI \\ University College Cork
}

\begin{abstract}
The stated aim of the EU Single Electricity Market (ESEM) is to link together EU electricity markets and get a unique electricity price across the EU. This target will be met by promoting efficient trading between price zones. Jointly with the ESEM, the EU has set separate ambitious targets for greenhouse gas emissions and renewable energy use: for emissions reduction these are stated as $20 \%$ lower than 1990 levels by $\mathbf{2 0 2 0}$, rising to $40 \%$ lower by 2030 and $85 \%$ lower by 2050 that will directly and indirectly promote the investment in renewables. By 2030, massive changes in EU electricity markets will take place. High investments in renewables associated with the necessity of efficient trades may result in network congestion, which rises the costs of the EU electricity system. In this work we use a PLEXOS model to verify the level of network congestion in 2030 and assuming interconnection according to the $\mathbf{1 0}$ year network development plan (TYNDP). We determine where further investment in interconnection can contribute to decreasing system costs at the EU level. The choice of the optimal investment is endogenised in the model. First we verify how the wholesale electricity prices change in EU countries. Second we check how profits are affected by the new investments. Finally we perform a welfare analysis including the emission savings achieved with the new investments in transmission networks. Our results indicate that individual interconnection upgrades reduce total system costs and therefore increase net welfare at the EU level. In addition, a shift from producer surplus to consumer surplus can be observed as a result of a higher level of interconnection.
\end{abstract}

\section{INTRODUCTION}

The creation of the European Single Electricity Market (ESEM) has been a stated aim of the European Union (EU) in order to promote efficient trading of electricity. ${ }^{1}$ The ambitious targets set by the European Commission on emission reduction for the electricity sector (and some large industry installations) through the EU Emissions Trading System (EU ETS) in Directive 2003/87/EC and for increased deployment of renewables in Directive 2009/28 will drive large increases in renewable electricity generation to 2030 and beyond. ESEM will play a crucial role in accommodating renewable generation by promoting interconnection between countries. This paper will analyse how the 10 year network development plan (TYNDP) made by ENTSO-E may be extended in order to minimise the ESEM costs in 2030. The differences between centralised

\footnotetext{
${ }^{1}$ See Directive 2009/72 on common rules for the internal market and Regulation (EC) 713/2009, which established the Agency for Cooperation of Energy Regulators. On the transition from regional to single market see http://ec.europa.eu/energy/sites/ener/files/documents/2010_ gas_electricity_markets.pdf.
}

and decentralised investment choices were already examined by [1], [2] and [3]. [4] analyse the impact of storage vs. interconnection investment on renewable curtailment by means of a linear optimisation model. However, there are no studies so far providing in-depth insight into the economic implications of lumpy interconnection invesments beyond the TYNDP for producers and consumers in the ESEM. This paper will endogenise the investment choices in interconnection between EU countries in order to understand how European welfare will change when projects that minimise the total system costs are undertaken. Moreover, we will investigate how the interconnection lines will affect individual EU countries. The paper is structured as follows. Section 2 highlights the methodology. Section 3 describes the data, Section 4 summarises the results and the final Section concludes.

\section{Methodology}

The software used to model the electricity market is the PLEXOS Integrated Energy Model which is a modelling tool used for electricity and gas market modelling and planning. ${ }^{2}$ The model optimises thermal and renewable generation and pumped storage subject to operational and technical constraints at hourly resolution. The objective function is to minimise total costs over the years across the full system. This includes operational costs, consisting of fuel costs and carbon costs; start-up costs consisting of a fuel offtake at start-up of a unit and a fixed unit start-up cost (see [5]). The resulting market price is defined as the marginal price at market schedule level and does not include any extra revenues from potential balancing, reserve or capacity markets or costs such as grid infrastructure cost, capital costs or taxes. These additional revenues or costs are not considered in our study. In our simulations a perfect market is assumed across the EU (i.e. no market power or bidding behaviour and power plants bid their short run marginal cost). A power plant portfolio is constructed for each Member State from the year 2013 to the year 2030. In all, approximately 2,220 individual thermal power plants are included in the model. Power plant capacities, efficiencies and fuel types are based on outputs from the PRIMES model for the EU countries. Interconnection between Member States is modelled as net transfer capacities and no

\footnotetext{
${ }^{2}$ The software is available here: http://energyexemplar.com/.
} 
interregional transmission is considered. Our analysis is made in three stages. First, we define the "Baseline" scenario, in which the line expansions defined by TYNDP are assumed to be effective in the system; we then assess whether there are congested lines in the system. We include in our model only the projects evaluated to be probable in the TYNDP. This choice gives us more accuracy in determining our results. ${ }^{3}$ Second, we include some possible expansion candidates (defined in the "Line expansions" scenario) of the congested lines into our model. The modelling horizon is 17 years, from 2013 to 2030. For each year, the algorithm endogenously evaluates whether the planned investment in transmission lines will reduce the total costs, and if the benefits associated to this investment will overcome the annual costs associated to the investment project. ${ }^{4}$ Third, we determine the impact of the new transmission lines on system prices, the generator's profits and the overall welfare. In order to quantify the costs associated with the interconnection we take into account that the EU supports several forms of financial help [6]. The involvement of financial institutions such as the European Investment Bank and the ad-hoc financed programmes proposed by the EU Commission make the funding of new transmission lines partially public. In particular the projects marked as of "common interest" are evaluated not only important for the EU security of supply, but also economically feasible, and then will be co-financed by the EU institutions [7]. In our scenario we assume that the interest rate of the line expansions will be $4 \%$ for a payback period of 60 years. Once the long-term schedule identifies the expansion candidates that are optimal and thus reduce total system costs relative to the "Baseline" scenario, we include these new lines into the system and run the model for 2030 in hourly resolution. As a robustness check we also run a scenario in which we assume that the projects will be mainly funded by private investors, with an interest rate of $6 \%$ and a payback period of 30 years. The optimisation tolerance used in the simulation is $0.1 \%$.

\section{HYPOTHESES}

The data used in this model has been described in [8]. Here we summarise the most significant hypotheses and explain the assumptions made on the transmission lines in detail.

\section{A. Fuel prices and demand}

The assumed fuel prices are consistent with the PRIMES scenarios. Gas price is assumed to be $65 € /$ boe, oil $93 € /$ boe and coal $24 € /$ boe, all in 2010 prices. We also consider a carbon price (ETS) of $40 € /$ tonne. It should be noted that these assumptions are rather high and will drive all our results. The PRIMES Reference scenario results detail overall electrical

\footnotetext{
${ }^{3}$ The report is available here: https://www.entsoe.eu/major-projects/ ten-year-network-development-plan/tyndp-2014/Pages/default.aspx. The description of the difference between the lines included in our model and the TYNDP is available from the authors upon request.

${ }^{4}$ Theoretically, cost minimisation will lead to competitive prices, which maximise consumer's surplus and will induce firms to behave competitively. We then consider total cost minimisation as the criterion to establish the optimality of the investment projects.
}

demand at an annual level only. The power system model constructed is at an hourly resolution, thus required an hourly electrical demand profile. This was done through attaining historic demand profiles from ENTSO-E for each Member State for the year 2012 and scaling them to 2030 overall projected demand detailed in the PRIMES results. In the Scenario examined, electricity demand rises by $12 \%$ between 2010 and 2030 on a EU level. Driving forces for this include greater penetration of appliances following economic growth, which mitigate the effects of eco-design standards on new products, increasing use of heat pumps and electro-mobility. For the purpose of this study, demand is assumed inelastic with respect to price; as a result, the same demand profiles are assumed in the scenario with new interconnection.

\section{B. Interconnection}

The transmission lines considered by our model include the existing level of interconnection and the majority of projects included in the TYNDP. Modelling results for the "Baseline" scenario show that several interconnection lines will be congested by 2030 (see Figure 1). We rank the existing lines by

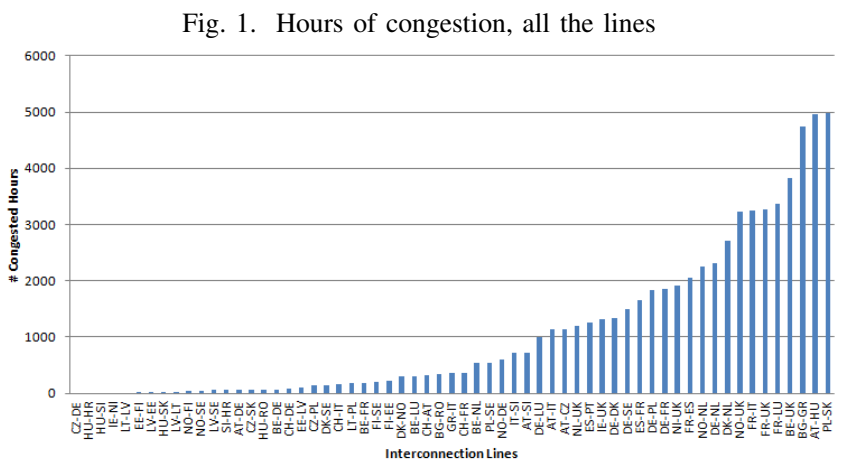

hours of congestion; we then identify as "severely congested" all the lines with more than 3000 hours of congestion per year, which are at the right side of Figure 1. We identified as "severely congested" the lines between Austria and Hungary, UK and France, France and Italy, Bulgaria and Greece, Poland and Slovakia, Norway and UK and Belgium and UK. For those lines, we plan some line extensions, using the data in the TYNDP on capacity and total costs. Some of the lines identified as heavily congested do not have any expansions planned in the TYNDP. As a result, we approximate the costs of this line using information on the line distance and the capacity required. In particular we use the data available for other interconnection lines to estimate the possible cost for the transmission lines between Poland and Slovakia and between Austria and Hungary. We estimate a polynomial regression between the costs included in the TYNDP and the relation between distance covered and interconnector capacity. We found an intercept equal to 41.03 and a coefficient of 0.0018 . We use these two parameters to estimate the costs associated to the interconnectors for which no information were available. 
TABLE I

LINE EXPANSIONS AND ASSOCIATED COSTS ( IN $2010 \mathrm{M} €$ )

\begin{tabular}{llllll}
\hline & $\begin{array}{l}\text { New } \\
\text { line ex- } \\
\text { pansion } \\
(\mathrm{MW})\end{array}$ & $\begin{array}{l}\text { Capacity } \\
\text { already in } \\
\text { the model } \\
\text { (MW) }\end{array}$ & $\begin{array}{l}\text { Min } \\
€ M\end{array}$ & $\begin{array}{l}\text { Max } \\
€ M\end{array}$ & $\begin{array}{l}\text { Mean } \\
€ M\end{array}$ \\
\hline FR-IT & $\mathbf{1 4 0 0}$ & 4000 & 1198 & 1415 & 1306 \\
FR-UK & $\mathbf{1 0 0 0}$ & 2500 & 349 & 650 & 500 \\
NO-UK & $\mathbf{1 4 0 0}$ & 1400 & 1586 & & 1586 \\
BE-UK & $\mathbf{1 0 0 0}$ & 1000 & 490 & 630 & 560 \\
BG-GR & $\mathbf{6 3 8}$ & 550 & 92 & & 92 \\
PL-SK & $\mathbf{6 0 0}$ & 600 & 283 & 318 & 300 \\
AT-HU & $\mathbf{3 0 0}$ & 300 & 202 & 242 & 222 \\
\hline
\end{tabular}

The expanded lines we considered in our model are shown by Table I. In the first column of the Table, we considered the installable new capacity in MW. We consider as expansion candidates new transmission lines with the same technical characteristics as the existing lines. In order to make the model choose the optimal level of interconnection between the congested lines, we offer 6 expansion candidates for each transmission line. Column 3 and 4 report the minimum and the maximum costs in 2010 prices, as assumed by the TYNDP. We scale the cost of the planned expansions according to the TYNDP when the size of the investment proposed to our model was different from the one already included in the TYNDP. Costs for the line expansions between Poland and Slovakia and Austria and Hungary have been calculated as explained below. The 4th column reports the average between the maximum and the minimum,which we use as an input in the model to make the model choose in which lines to invest. Thus, we run the "Line extensions" scenario, which includes the investments in new transmission lines.

\section{Results}

Investment in additional new lines is undertaken only between Bulgaria and Greece. ${ }^{5}$ In order to understand the impact of the new transmission lines, we compare the "Baseline" and the "Line extensions" scenarios, focusing on four different aspects. First we investigate the impact of new lines on the existing network. Second, we check how the prices and the profits change in the interested regions and in Europe after the investment is undertaken. Third, we focus on the environmental impact of the new lines checking how emissions and emission costs change in the two scenarios. Finally we examine the welfare gains associated with the "Line extensions" model. All results are reported for the year 2030 in the following.

\section{A. Interconnection lines}

In the "Line extensions" scenario, ranking the network lines by the hours congested give similar results as in the "Baseline" scenario. Again the most congested interconnectors are the transmission lines between Austria and Hungary (4870

\footnotetext{
${ }^{5}$ Also in the robustness check scenario with $6 \%$ of interest rate and 30 years investment horizon the results do not change
}

h) and between Poland and Slovakia $(4670 \mathrm{~h})$. Also, the interconnection between Greece and Bulgaria (including the upgrades) stays heavily congested, even though the number of congested hours can be reduced to approx. 3700 per year on average through the new interconnection lines. Finally, as no line expansion was selected for France-UK, Belgium-UK or Norway-UK, all these interconnectors stay congested for more than 3000 hours per year. In addition, the new lines built into the system bring some congestion in lines that were not congested in the "Baseline" scenario, as shown by Figure 2 .

Fig. 2. Congested hours after the investment in new lines: baseline vs new investment

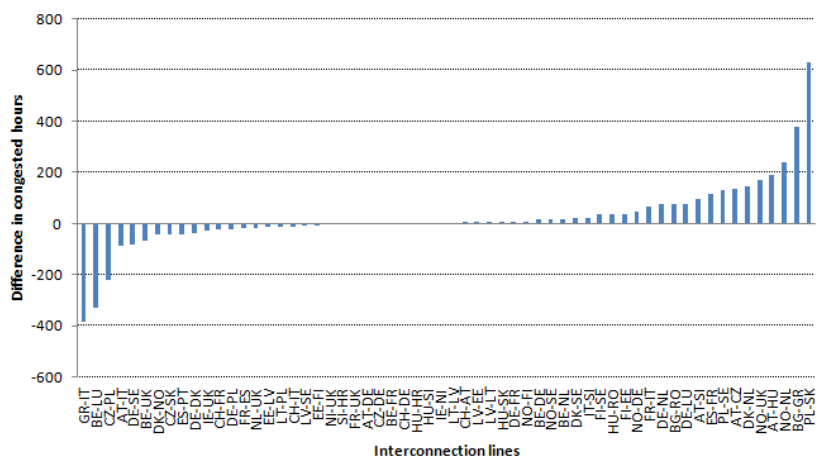

\section{B. Prices and profits}

To better understand the effects of the new lines in the EU system, we investigate how wholesale prices and the generator's profits change between the "Baseline" and the "Line extensions" scenarios. Only the prices related to the wholesale market are considered in our analysis. Thus, in order to analyse the consumer surplus and the producer profits we make the assumption that the wholesale price partially reflects both the retail and the balancing prices. This approximation may lead to several biases that should be discussed. The profits of thermal generators are potentially underestimated, because we do not take the balancing market into account. With high renewable penetration in the market, thermal generators are frequently providing electricity on the balancing market, in order to compensate the intermittency of the renewable plants. At the same time, the benefits for the consumers are potentially biased, because in our model we do not take into account the forward market; retail prices will be higher than the wholesale prices and this is amplified if retail markets are not competitive and consumers do not switch their provider frequently [9], [10].

1) Prices: The average European wholesale electricity price goes from $88 € / \mathrm{MWh}$ in the "Baseline" to approx. $87 € / M W h$ in the "Line extensions" scenario. Thus, the investment in new transmission lines is beneficial for European consumers, as on average, the electricity price decreases by $1 \%$. The effects of the new lines between Greece and Bulgaria are positive for the consumers in both countries, as the prices 
are lower than in the "Baseline" scenario. The wholesale electricity prices decrease in Bulgaria from 92 to $86 € / \mathrm{MWh}$. Moreover, the price in Greece decreases by more than 5 $€ / \mathrm{MWh}$, going from $98 € / \mathrm{MWh}$ to below $93 € / \mathrm{MWh}$. In the other heavily congested areas, there is almost no effect on the prices. In Belgium and UK the prices increase slightly; for all the other countries interested in line congestion (Poland, Slovakia, Austria and Hungary) the electricity price decreases. This is an expected result: as more interconnection is built between countries, more the prices will tend to converge to the average EU price.

2) Generator's profits: We calculate the generator's profits as follows:

$$
\pi_{s, i, t}=\sum_{t}\left(p_{s} * \text { Generation }_{s, i, t}-T C_{s, i, t}\right)
$$

In which $t$ is the hour, $i$ the generator's type (renewable or thermal), $s$ is the considered scenario. $T C$ are the total costs of the generator which include the start up, the emission and the actual generation costs. At the European level, both thermal and renewable generators will be worse off after the investment in new lines, as shown by the Table below: The European

TABLE II

PROFITS, BILLIONS OF $€$

\begin{tabular}{rrrr} 
& Baseline & New Lines & \% change \\
\hline RES & 139.3 & 138.6 & $-0.50 \%$ \\
Thermal & 64.1 & 63.6 & $-0.81 \%$ \\
\hline TOT & 203 & 202 & $0.60 \%$
\end{tabular}

overall profits are slightly lower in the new lines scenario, as they go from 205 billions of euro to 202 billions. Proportionally, renewable generators loose less than the thermal generators when the new lines are built because they are not the marginal units. The lower electricity prices with respect to the "Baseline" scenario are the driving factor of the lower profits in the "Line extensions" scenario. Finally, we compare the profits of thermal and renewable generators in Greece and Bulgaria (see Table III). The profits for both thermal

TABLE III

GENERATOR PROFITS, $€ / M$

\begin{tabular}{rrrr} 
& Baseline & New Lines & \% change \\
\hline Bulgaria & 821 & 783 & $-4.9 \%$ \\
Greece & 2,323 & 2,264 & $-2.6 \%$ \\
\hline
\end{tabular}

(a) RES plants

\begin{tabular}{rrrr} 
& Baseline & New Lines & \% change \\
\hline Bulgaria & 1,197 & 1,036 & $-15.5 \%$ \\
Greece & 530 & 263 & $-101.3 \%$ \\
\hline
\end{tabular}

(b) Thermal plants

and renewables are lower in the "Line extensions" scenario than in the "Baseline" for both Bulgaria and Greece. More interconnection will accommodate the renewable generation better, driving the prices down. As the balancing market is not considered in our analysis, the lower prices will have the effect of lowering the profits for all the generators.

3) IC profits: We calculate the profits made by the owners of the interconnectors as:

$$
\pi_{I C}=\sum_{t} a b s\left(p_{i}-p_{j}\right)_{t} * a b s(\text { NetImport })_{t}
$$

in which $t$ are the day of the year, $p_{i}$ is the wholesale electricity price of the exporting country and $p_{j}$ is the wholesale electricity price of the importing country. NetImport is the flow of net imports from the first country to the other. At the European level, interconnection profits will decrease, from 4720 to 4607 millions of euros. Table IV focus on the profits made by the IC between Bulgaria and Greece. The absolute

TABLE IV

IC PROFITS PER MW TRADED, BULGARIA AND GREECE

\begin{tabular}{rrr} 
& IC total profits $(€ / \mathrm{M})$ & IC profits per MW \\
\hline Baseline & 37 & 326 \\
New Lines & 83 & 178 \\
\hline$\Delta$ & 46 & -148 \\
\hline$\%$ change & $55.6 \%$ & $-82.7 \%$ \\
\hline
\end{tabular}

value of net profits for the owners of the new interconnectors is positive, and approximately equal to $46 € / \mathrm{M}$, but per MW the profits of the IC owner decreases, as shown in Table IV. We assume that the owner of the interconnector is the EU, as the project was financed assuming the involvement of financial institutions as the EIB. However, the positive profit made on the congested line between Greece and Bulgaria is not enough to compensate the losses on other lines. At the EU level, the profitability of network lines decrease between the "Baseline" and the "Line Extensions" scenario by $1 € / \mathrm{M}$.

\section{Emissions}

The investment in new interconnection lines has a negative effect on the emissions for Europe. Overall emissions increase by almost 3 millions of tonnes with the new lines built into the system. Assuming that the emission costs are of $40 € /$ tonne, the associate expenditure for Europe will be of $119 € / \mathrm{M}$. The new interconnector between Greece and Bulgaria displaces the Greek CCGTs, and increase the generation by coal and lignite plants in Bulgaria. The relative high price of gas assumed in our model partially justifies this result. The effects for Bulgaria and Greece are shown in detail in the following Table.

TABLE V

EMISSION COSTS, M€

\begin{tabular}{rrrr} 
& Baseline & New Lines & Delta \\
\hline Bulgaria & 567 & 871 & 304 \\
Greece & 730 & 612 & -119 \\
\hline
\end{tabular}




\section{Welfare}

The total system costs, minimised by the PLEXOS algorithm, are 49 millions lower in the "Line extensions" scenario than in the "Baseline" scenario (-0.03\%). As a result, the investment in new lines is profitable for the European system as a whole. However, as shown by the results on prices and profits, there is a mixed evidence about who gains and looses from higher interconnection. Consumers will benefit of lower prices and lower emissions. The profits of generators and interconnector's owners will decrease. In order to summarise the gains and losses, we calculate the European welfare in the two scenarios. Welfare is defined as the sum of the consumer surplus, generation profits and interconnection profits. Table

TABLE VI

WELFARE ANALYSIS, EUROPE, M€

\begin{tabular}{rc}
\hline Consumers & 3,088 \\
Producers & $-2,403$ \\
IC profits & -1 \\
\hline Net welfare & $\mathbf{6 8 3}$ \\
IC costs & -13 \\
\hline Welfare + IC costs & $\mathbf{6 7 0}$ \\
\hline
\end{tabular}

VI shows that the gains for consumers related to lower prices and lower emission costs offset the losses made by producers and interconnector owners. As a result, the investment in new lines will lead to 683 million gains for Europe. This number should be taken carefully because it comes from a number of assumptions. First, fuel prices are assumed quite high for gas and oil. As gas is frequently the marginal fuel in the EU system, this assumption makes renewable generation more profitable by definition. Second, we do not consider here any potential changes in the final demand. Demand elasticity may play an important role in reducing the system prices and further analysis will be required in order to understand its impact. Finally, just the wholesale electricity market was considered in our analysis. Retail and balancing market are not the object of our simulation, so numbers from Table VI should be taken as a reference, and not considered in their absolute values. The annual cost for the interconnection, under the assumption of $4 \%$ interest rate and 60 years of economic life is of 13 millions of euro. Included this into our analysis the net gain will be of 670 millions. Emission costs will rise by 119 millions, but they are included in the profits of the generators. Looking at Bulgaria and Greece more closely, the new investment in transmission lines between the two countries will have a positive effect on both countries, as the gains for consumers will offset the losses of the producers. In particular, Bulgaria will have a net welfare of 51 millions and Greece will have a net welfare of 69 millions.

However, the positive European welfare justifies the communitarian approach to the investment lines, as also suggested by [3] based on evidence for the NordPool market. Compensation mechanisms should be considered in order to promote the investment in infrastructure.

\section{CONClusion}

This paper studies the impact of investment in new transmission lines between EU countries. We run two scenarios. In the first, we assume that most of the transmission lines envisaged by the ENTSO-E TYNDP will be operational in 2030. In the second, we include additional transmission lines in the model that minimise the total system costs. As a result, we run the TYNDP model with three new interconnectors between Bulgaria and Greece. Our results show that new lines lead to significant welfare gains at the EU level. Consumers will face lower wholesale electricity prices and lower emissions. However, generators and interconnectors' owners will have lower profits. There is a mixed evidence about emission effects for the two countries directly affected by the interconnectors. Bulgaria will increase its emissions, while Greece will reduce them. These results emphasise that interconnector projects should be promoted and coordinated at the EU level.

\section{ACKNOWLEDGMENT}

This material is based upon works supported by the Science Foundation Ireland, by funding Valeria Di Cosmo, under Grant No. SFI/09/SRC/E1780. The opinions, findings and conclusions or recommendations expressed in this material are those of the authors and do not necessarily reflect the views of the Science Foundation Ireland. The authors wish to acknowledge the use of FICO Xpress Optimiser through Academic partnership. Available online at http://www.fico.com

\section{REFERENCES}

[1] G. Brunekreeft, K. Neuhoff, and D. Newbery, "Electricity transmission: An overview of the current debate," Utilities Policy, vol. 13, pp. 73-93, 2005.

[2] G. Brunekreeft, "Regulatory issues in merchant transmission investment," Utilities Policy, vol. 13, pp. 175-186, 2005.

[3] M. . Lynch, R. S. Tol, and M. J. O’Malley, "Optimal interconnection and renewable targets for north-west europe," Energy Policy, vol. 51, no. C, pp. 605-617, 2012. [Online]. Available: https://ideas.repec.org/ a/eee/enepol/v51y2012icp605-617.html

[4] D. Gunkel, F. Kunz, T. Mller, A. von Selasinsky, and D. Mst, "Optimal interconnection and renewable targets for north-west europe," 2012.

[5] J. Deane, G. Drayton, and B. O'Gallachoir, "The impact of sub-hourly modelling in power systems with significant levels of renewable generation," Applied Energy, vol. 113, pp. 152 - 158, 2014. [Online]. Available: http://www.sciencedirect.com/science/article/ pii/S030626191300593X

[6] C. von HIRSCHHAUSEN, "Financing trans-european energy infrastructures past, present and perspectives," Notre Europe Institute, Tech. Rep., 2013. [Online]. Available: http://www.notre-europe.eu/ media/c.vonhirschhausen-energyinfrastructures-notre-europe-nov2011. pdf?pdf $=$ ok

[7] E. Commission, "Progress towards completing the internal energy market," European Commission, Tech. Rep., 2014.

[8] S. Collins, P. Deane, and V. Di Cosmo, "Network transmission versus demand response: what is the impact on renewables? an application to ireland and france," 2016.

[9] C. Defeuilley, "Retail competition in electricity markets," Energy Policy, vol. 37, no. 2, pp. 377 - 386, 2009. [Online]. Available: http://www.sciencedirect.com/science/article/pii/S030142150800387X

[10] J. Farrell and P. Klemperer, Coordination and Lock-In: Competition with Switching Costs and Network Effects, M. Armstrong and R. Porter, Eds. Elsevier, 2007. 